정규논문 (Regular Paper) 방송공학회논문지 제18권 제1호, 2013년 1월 (JBE Vol. 18, No. 1, January 2013)

http://dx.doi.org/10.5909/JBE.2013.18.1.10

ISSN 2287-9137 (Online) ISSN 1226-7953 (Print)

\title{
$\mathrm{DCT}$ 계수 분포를 이용해 추출한 edge 방향성에 기반한 새로운 적응적 보간 기법 \\ 김 재 훈 $^{a)}$, 김 기 백 ${ }^{a)}$, 전 광 길 ${ }^{b)}$, 정 제 창 ${ }^{\natural}$
}

\section{New Adaptive Interpolation Based on Edge Direction extracted from the DCT Coefficient Distribution}

\author{
Jaehun Kim $^{\text {a)}}$, Kibaek Kim ${ }^{\text {a) }}$, Gwanggil Jeon ${ }^{\text {b) }}$, and Jechang Jeong ${ }^{\text {a) }}$ \\ 요 약
}

현재 멀티미디어 장치와 사용자의 요구가 다양해짐에 따라 이를 충족시키기 위하여 이미지 크기는 장치에서 지원하는 해상도나 사 용자의 요구에 맞게 조정되어야 한다. 이미지 보간 기법은 크게 공간 도메인과 주파수 도메인에서 수행 될 수 있다. 일반적으로 공간 도메인에서의 보간 방법은 주파수 도메인의 보간 기법에 비해 상대적으로 주관적인 화질 측면에서 좋은 성능을 나타내지만 오버 스무 딩 현상으로 인해 객관적인 성능이 낮다. 반대로 주파수 도메인에서의 업샘플링 방법은 객관적인 화질 측면에서 좋은 성능을 나타내지 만 블록 열화 현상이 나타나 주관적인 화질 측면 성능이 낮다. 주파수 도메인에서의 보간 기법은 블록 열화 현상 외에도 모든 블록에 대해 동일한 방법으로 고주파 성분을 채워 넣기 때문에 영상의 edge가 많은 부분에서 주관적인 화질 성능을 떨어뜨린다. 본 논문에서 는 DCT 계수 분포를 이용해 분류된 edge 방향에 따라 공간 도메인과 주파수 도메인에서의 보간 기법을 적응적으로 사용하는 알고리 듬을 제안한다. 제안하는 알고리듬은 두 도메인의 장점을 모두 가지고 있다. 실험 결과를 통해 제안하는 알고리듬이 주관적인 화질 측 면의 성능 향상과 함께 객관적인 화질도 향상됨을 알 수 있다.

\begin{abstract}
Nowadays, video technology has been successfully improved creating tremendous results. As video technology improve, multimedia devices and demands from users are diversified. Therefore, a video codec used in these devices should support various displays with different resolutions. The technology to generate a higher resolution image from the associated low-resolution image is called interpolation. Interpolation is generally performed in either the spatial domain or the DCT domain. To use the advantages of both domains, we have proposed the new adaptive interpolation algorithm based on edge direction, which adaptively exploits the advantages of both domains. The experimental results demonstrate that our algorithm performs well in terms of PSNR and reduces the blocking artifacts.
\end{abstract}

Keyword : Up-sampling, interpolation, DCT, wiener filter 


\section{I. 서 론}

현재 홈 네트워크와 브로드밴드 컨버전스 기술 등의 발달 로 언제, 어디서든 원하는 사진 또는 비디오 영상을 볼 수 있게 되었다. 또한, 디스플레이 장치 기술이 급속도로 발전 하면서 그 종류가 다양해졌다. 현재 사용자들은 표준화질 텔 레비전(SDTV), 고화질 텔레비전(HDTV)에서부터 휴대폰, 태블릿PC에 이르기까지 다양한 해상도의 디스플레이 장치 를 이용해 영상을 보고 있다. 멀티미디어 장치의 다양화와 더불어 사용자들의 요구 또한 다양해지고 있다. 이런 환경에 맞게 멀티미디어 장치에 사용되고 있는 비디오 코덱 기술들 도 다양한 해상도의 영상을 지원할 수 있어야 한다. 이미지 업샘플링은 저해상도의 영상을 이용해 고해상도 영상을 만 들어 내는 기술이다. 현재 이미지 업샘플링은 공간 확장성을 제공하는 스케일러블 비디오코딩(scalable video coding) 표 준에 사용되는 기술이다. 스케일러블 비디오코딩에서 업샘 플링 된 영상의 품질에 따라 전반적인 코딩 효율이 결정되므 로 업샘플링의 성능이 매우 중요하다 ${ }^{[1,11]}$.

H.264/AVC, MPEG-4, H.263, JPEG 등 이전 비디오 코 덱 표준과 $\mathrm{HEVC}$ 같은 차세대비디오 코덱들은 효율적으로 데이터를 압축하기 위해 이산코사인 변환(discrete cosine transform: DCT)을 사용해 영상을 압축 도메인으로 변환시 킨다. DCT는 에너지 집중 현상(energy compaction) 성능이 뛰어나기 때문에 영상 압축분야에서 널리 사용되는 변환 기술이다. 영상을 압축 도메인에서 직접 다루는 기술은 많 은 이점을 가져 올 것이고, 업샘플링도 압축 도메인에서 직 접 수행될 수 있다.

이미지 업샘플링은 크게 공간 도메인(spatial domain) 또 는 DCT도메인(DCT domain)에서 수행되는 기술로 분류할

a) 한양대학교 전자컴퓨터통신공학(Department of Electronics and Computer Engineering, Hanyang University)

b) 인천대학교 임베디드시스템공학과(Department of Embedded Systems Engineering, University of Incheon)

‡ Corresponding Author : 정제창 (Jechang Jeong) E-mail: jjeong@hanyang.ac.kr Tel: +82-2-2220-4369

※ 이 논문은 2012 년도 정부(교육과학기술부)의 재원으로 한국연구재단의 기초연구사업 지원을 받아 수행된것임(2012-0001584).

Manuscript received September 10, 2012 Revised Novemver 6, 2012 Accepted December 17, 2012
수 있다. 대표적인 공간 도메인에서의 이미지 업샘플링 기 법은 양 선형(bi-linear), 2차 선형(Bi-cubic), S-Spline, 6-탭 위너 필터(6-tap wiener filter) 등이 있다 ${ }^{[2-5,}{ }^{12]}$. 이 중에서 6-tap wiener filter는 H.264/AVC 와 SVC 비디오 코덱에서 업샘플링 기법으로 사용되고 있는 대표적인 기법이다. 공 간 도메인에서의 업샘플링 기법은 주변 화소들의 정보를 이용해 이미지를 보간하기 때문에 주관적인 화질에서 좋은 성능을 보여주지만 오버스무딩(over-smoothing) ${ }^{[12]}$ 현상을 발생시켜 업샘플링된 영상의 객관적인 성능을 떨어뜨린다. DCT 도메인에서의 업샘플링은 제로 패딩(zero-padding) 과 하이브리드(hybrid) 기법이 있다 ${ }^{[6-9]}$. 이 기법들은 공간 도메인에서의 업샘플링보다 over-smoothing 효과가 적게 나타나 상대적으로 객관적인 화질이 높게 나오지만 블록 열화현상이 나타나 주관적인 화질에서 낮은 성능을 보여준 다. DCT 도메인에서의 업샘플링은 블록 열화 현상 외에도 모든 블록에 대해 동일한 방법으로 고주파 성분을 채워 넣 기 때문에 영상의 edge가 많은 부분에서 주관적인 화질 성 능을 떨어뜨린다.

본 논문에서는 객관적인 화질이 좋은 DCT 도메인에서의 업샘플링 기법과 주관적인 화질이 좋은 공간 도메인에서의 업샘플링 기법을 블록의 edge 방향에 따라 적응적으로 사 용하는 알고리듬을 제안한다. 이미지를 $4 \times 4$ 블록 단위로 $\mathrm{DCT}$ 하고 그 계수를 이용해 블록의 edge 방향을 평탄한 블 록(flat), 수평방향(horizontal), $45^{\circ}$ 대각방향(increase diagonal), 수직방향(vertical), $135^{\circ}$ 대각방향(decrease diago$\mathrm{nal}$ ), 방향성이 없는 복잡한 패턴을 갖는 블록(non-direction)의 6가지로 분류한다. 분류된 edge 방향의 특성을 고려 해 블록 단위로 DCT도메인과 공간도메인에서의 보간 기법 을 적응적으로 사용해 $8 \times 8$ 블록으로 업샘플링 한다.

본 논문의 구성은 다음과 같다. II장에서는 기존 업샘플 링 기법에 대하여 간략히 소개를 하고, III장에서는 다음 세 순서대로 제안하는 기법을 자세히 설명한다. (1) DCT 계수 분포 분석, (2) DCT 도메인에서 edge방향 추출 방법, (3) edge 방향에 기반한 적응적 업샘플링 알로리듬. 그리고 IV 장에서는 실험결과를 통해 기존 알고리듬과 제안하는 알고 리듬의 성능을 비교 분석하고, 마지막으로 $\mathrm{V}$ 장에 결론을 맺는다. 


\section{II. 전형적인 이미지 업샘플링 기법}

\section{1. 공간도메인에서의 6-탭 위너 필터 (6-tap Wiener} Filter)

6-탭 위너 필터의 6 화소에 대한 각 가중치를 나타내는 필터 계수 ${ }^{[10]}$ 는 (1)과 같다.

$$
\{1,-5,20,20,-5,1\} / 32
$$

그림 1 은 원본화소와 업샘플링된 화소의 위치 관계를 나 타낸고, 회색 픽셀은 원본 화소를 나타낸다. 예를 들어, 그림 1 의 $\mathrm{a}$ 위치의 업샘플링 된 화소를 구하기 위해서는 $\mathrm{A}, \mathrm{B}, \mathrm{C}$, $\mathrm{D}, \mathrm{E}, \mathrm{F}$ 에 대해 수직방향으로 6-탭 필터를 적용해야 한다.

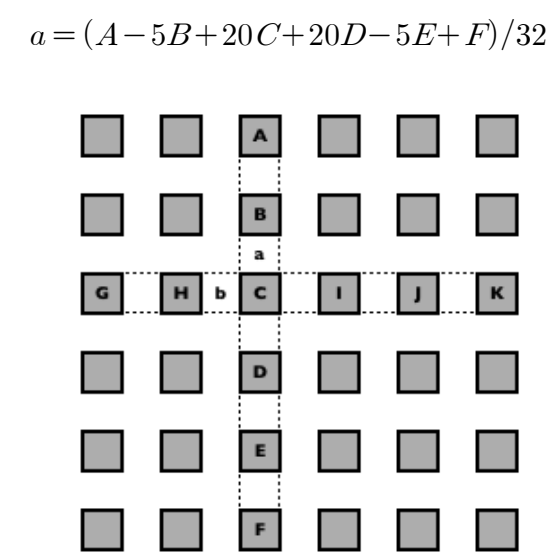

그림 1. 원본화소와 업샘플링된 화소의 위치 관계

Fig. 1. Position of original pixel and up-sampled pixel

\section{DCT 도메인에서의 제로 패딩 기법 (Zero-Padding) $^{[6]}$}

$\mathrm{DCT}$ 도메인에서의 업샘플링 방법은 이미지를 블록 단 위로 분할 후 가가 블록을 (3)의 DCT를 수행한다.

$$
\begin{aligned}
& F(u, v)=C_{u} C_{v} \sum_{i=0}^{N-1 N-1} \sum_{j=0} \cos \frac{(2 i+1) u \pi}{2 N} \cos \frac{(2 j+1) v \pi}{2 N} f(i, j) \\
& C_{u} C_{v}=\left\{\begin{array}{l}
\frac{1}{\sqrt{N}} \text { for } u, v=0 \\
\sqrt{\frac{2}{N}} \text { otherwise. }
\end{array}\right.
\end{aligned}
$$

여기서 $\mathrm{F}(\mathrm{u}, \mathrm{v})$ 와 $\mathrm{f}(\mathrm{i}, \mathrm{j})$ 는 각각 공간 도메인과 주파수 도메 인에서의 블록을 나타낸다.

그 후에 업샘플링 되는 블록의 좌측 상단에 DCT 계수를 채우고, 채워진 DCT 계수 영역을 제외한 나머지 고주파 영 역에 제로(zero)를 패딩하여 다시 역변환(inverse DCT: IDCT)하는 방법이다. (4)는 DCT 도메인에서의 제로 패딩 방법을 나타낸다.

$$
S_{\text {zero_padding }}=I D C T\left(\left(\begin{array}{cc}
f_{\text {orig_low }} & 0 \\
0 & 0
\end{array}\right)\right)+I D C T\left(\left(\begin{array}{ll}
0 & 0 \\
0 & 0
\end{array}\right)\right)
$$

여기서 forig_low는 원본 이미지 블록의 DCT 후 DCT 도 메인에서의 DCT 계수를 나타낸다. 이 방법은 공간 도메인보 다 over-smoothing 효과가 적게 나타나 상대적인 화질이 높 게 나오지만 고주파 성분을 0 으로 패딩하기 때문에 블록열화 현상이 나타나 주관적인 화질에서 낮은 성능을 보여준다.

\section{DCT 도메인에서의 hybrid 방법 (Hybrid) ${ }^{[9]}$}

하이브리드 방법은 제로 패딩 방법에서 고주파 영역을 0 으로 패딩하면서 발생하는 블록열화 현상으로 인해 주관 적인 화질이 저하되는 현상을 보완하는 방법이다. 먼저 공 간 도메인에서 6-탭 위너 필터를 사용해 업샘플링하고, 그 업샘플링 된 이미지를 블록 단위로 DCT를 수행한다. 그리 고 제로 패딩 방법에서 0 으로 패딩하는 고주파 위치에 6-탭 필터로 업샘플링 된 이미지의 해당 블록의 고주파 성분을 넣어 준다. 그 후의 과정은 제로 패딩 방법과 동일하다. (5) 는 하이브리드 방법을 나타낸다.

$S_{\text {hybrid }}=I D C T\left(\left(\begin{array}{cc}f_{\text {orig_low }} & 0 \\ 0 & 0\end{array}\right)\right)+I D C T\left(\left(\begin{array}{cc}0 & f_{W h i g h}^{1} \\ f_{W h i g h}^{2} & f_{W h i g h}^{3}\end{array}\right)\right)$

여기서 fW_high는 6-탭 위너 필터를 사용해 업샘플링 된 이미지를 $\mathrm{DCT}$ 한 고주파 성분을 나타낸다.

\section{III. 제안하는 알고리듬}

\section{DCT 계수 분포 분석}

DCT는 에너지 집중 현상(energy compaction)이 뛰어나 
기 때문에, 영상처리나 손실 데이터 압축 분야에서 널리 사 용된다. 제안하는 알고리듬에서는 블록 단위로 DCT를 수 행하고, 그 계수를 분석하여 edge 방향을 추출한다. 블록의 크기는 업샘플링 환경과 사용자의 의도에 맞게 설정할 수 있다. 본 논문에서는 $4 \times 4$ 블록단위로 $\mathrm{DCT}$ 한 계수를 분석 하였다 ${ }^{[1]}$. (6)은 $4 \times 4$ 블록단위 DCT를 나타낸다.

$F(u, v)=\frac{C_{u} C_{v}}{2} \sum_{i=0 j=0}^{3} \sum^{3} \cos \frac{(2 i+1) u \pi}{8} \cos \frac{(2 j+1) v \pi}{8} f(i, j)$
$C_{u} C_{v}=\left\{\begin{array}{cl}\frac{1}{\sqrt{2}} & \text { for } u, v=0 \\ 1 & \text { otherwise. }\end{array}\right.$

여기서 $\mathrm{F}(\mathrm{u}, \mathrm{v})$ 는 $\mathrm{DCT}$ 계수 블록을, $\mathrm{f}(\mathrm{i}, \mathrm{j})$ 는 화소 블록을 나타낸다.

그림 2에서 $4 \times 4 \mathrm{DCT}$ 계수의 특징을 보여주는 블록이다. 여기서 블록의 가장 좌측 상단의 계수를 $\mathrm{DC}$ 라 부르고, 이 값은 블록의 평균 밝기 정보를 나타낸다. $\mathrm{DC}$ 를 제외한 나 머지 계수를 $\mathrm{AC}$ 성분이라 부르고, 이 값들은 특정 방향에 대한 회색도(gray level)의 변화를 나타낸다.

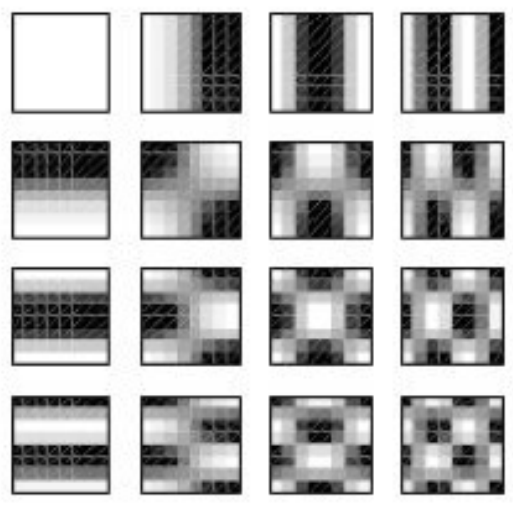

그림 2. $4 \times 4$ DCT 계수

Fig. 2. $4 \times 4$ DCT Coefficients

그림 2에서 볼 수 있듯이, $\mathrm{AC}$ 성분들이 블록의 어느 방 향에 대한 정보를 가지고 있는지 알 수 있다. 이 정보들을 이용해 정확한 edge 방향 추출을 위하여 $\mathrm{AC}$ 성분의 분포를 분석하였고, 이를 위해 $\mathrm{AC}$ 성분을 다음 3 가지 그룹으로 분 류하였다. 수직방향의 edge 성분을 가지고 있는 첫 번째 행 (row)의 절대 합을 SR (absolute Sum of row), 수평방향의 edge 성분을 가지고 있는 첫 번째 열(column)의 절대 합을 $\mathrm{SC}$ (absolute Sum of Column), 대각방향의 edge 성분을 가 지고 있는 나머지 $\mathrm{AC}$ 계수의 절대 합을 $\mathrm{SD}$ (absolute Sum of Diagonal)로 분류하였다. SR, SC, SD을 (7)에 나타내었 고, $\mathrm{DC}$ 는 제외한다.

$$
\begin{aligned}
& S R=\sum_{u=1}^{3}|F(u, 0)|, \\
& S C=\sum_{u=1}^{3}|F(0, u)|, S R=\sum_{u=1}^{3}|F(u, u)|
\end{aligned}
$$

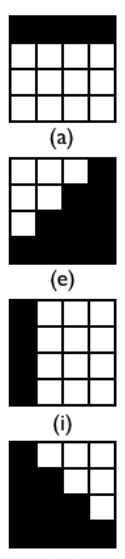

(m)

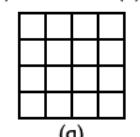

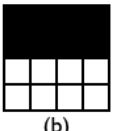

(b)
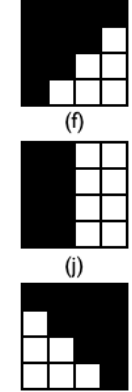

(n)

(o)

(g)
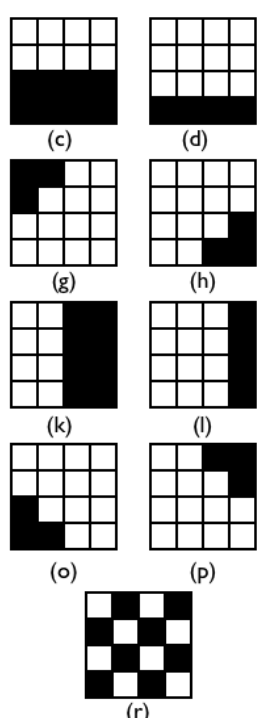

그림 3. 실험 블록: $0^{\circ}(\mathrm{a} \sim \mathrm{d}), 45^{\circ}(\mathrm{e} \sim \mathrm{h}), 90^{\circ}(\mathrm{i} \sim), 135^{\circ}(\mathrm{m} \sim \mathrm{p})$, flat(q), non-direction( $r$ )

Fig. 3. Test blocks with angles of $0^{\circ}(\mathrm{a} \sim \mathrm{d}), 45^{\circ}(\mathrm{e} \sim \mathrm{h}), 90^{\circ}(i \sim 1)$, $135^{\circ}(m \sim p)$, flat $(q)$, non-direction(r)

$0^{\circ}, 45^{\circ}, 90^{\circ}, 135^{\circ}$ 의 방향성과 flat과 non-direction 패턴 을 가지는 22 개의 실험 블록을 만들어 실제 $\mathrm{AC}$ 계수들의 분포를 분석하였다. 그림 3 은 실험에 사용한 22 개의 실험 블록을 보여주고, 여기서 검정색 화소는 0 , 흰색 화소는 255 값을 가지는 블록이다. 표 1 에 6 개의 방향성에 대한 $\mathrm{SR}, \mathrm{SC}, \mathrm{SD}, \mathrm{DC}$ 성분의 비율을 표시하였다. 표1 의 결과에 서 알 수 있듯이, 수평 방향에서는 SC 성분의 비율이 가장 높게 나타난다. 그리고 수직방향에 대해서는 $\mathrm{SD}$ 성분이 가 
장 높은 비율을, 대각 방향에 대해서는 $\mathrm{SD}$ 성분의 비율이 가장 높은 것을 확인할 수 있다. 하지만 $45^{\circ}$ 와 $135^{\circ}$ 대각 방향에서 $\mathrm{SD}$ 성분의 비율이 똑같은 것을 알 수 있다. 두 방 향을 구분하기 위해 $(\mathrm{e})$ 와 $(\mathrm{m})$ 블록의 $\mathrm{AC}$ 계수를 분석하였 다. 그 결과, $45^{\circ}$ 에서는 $\mathrm{AC}$ 계수들의 분포가 대칭(symmetric) 이고 $135^{\circ}$ 에서는 반대칭(anti-symmetric) 이었다.

\section{DCT 도메인에서 edge방향 추출 방법}

현재 업샘플링 하고자 하는 블록의 방향성을 분류하기 전에 분산(variance)을 이용해서 그 블록이 edge성분을 가 지고 있는지 아니면 평평한 영역인지를 결정한다. DCT 도 메인에서 블록의 분산은 다음과 같다.

$$
\sigma^{2}=\frac{1}{N^{2}} \sum_{u=0}^{3} \sum_{v=0}^{3} F(u, v)^{2} \quad(u, v) \neq(0,0)
$$

Parseval 이론에 의해서 DCT 도메인에서의 블록의 분산

표 1. 실험 블록에 대한 $\mathrm{SR}, \mathrm{SC}, \mathrm{SD}, \mathrm{DC}$ 의 비율

Table 1. Percentage of SR, SC, SD, and DC in test blocks in Fig. 3

\begin{tabular}{|c|c|c|c|c|c|}
\hline angle & \# in Fig. 3 & SR & SC & SD & DC \\
\hline \multirow{4}{*}{$0^{\circ}$} & (a) & 0 & 48.69 & 0 & 51.31 \\
\cline { 2 - 6 } & (b) & 0 & 56.63 & 0 & 43.37 \\
\cline { 2 - 6 } & (c) & 0 & 56.63 & 0 & 43.37 \\
\cline { 2 - 6 } & (d) & 0 & 48.69 & 0 & 51.31 \\
\hline \multirow{4}{*}{$45^{\circ}$} & (e) & 17.83 & 17.83 & 41.94 & 22.40 \\
\cline { 2 - 6 } & (f) & 17.83 & 17.83 & 41.94 & 22.40 \\
\cline { 2 - 6 } & (g) & 13.64 & 13.64 & 32.23 & 40.49 \\
\cline { 2 - 6 } & (h) & 13.64 & 13.64 & 32.23 & 40.49 \\
\hline \multirow{4}{*}{$90^{\circ}$} & (i) & 48.69 & 0 & 0 & 51.31 \\
\cline { 2 - 6 } & (j) & 56.63 & 0 & 0 & 43.37 \\
\cline { 2 - 6 } & (k) & 56.63 & 0 & 0 & 43.37 \\
\cline { 2 - 6 } & (l) & 48.69 & 0 & 0 & 51.31 \\
\hline \multirow{4}{*}{$135^{\circ}$} & (m) & 17.83 & 17.83 & 41.94 & 22.40 \\
\cline { 2 - 6 } & (n) & 17.83 & 17.83 & 41.94 & 22.40 \\
\cline { 2 - 6 } & (o) & 13.64 & 13.64 & 32.23 & 40.49 \\
\cline { 2 - 6 } & (p) & 13.64 & 13.64 & 32.23 & 40.49 \\
\hline Flat & (q) & 0 & 0 & 100 & 0 \\
\hline Non-direction & (r) & 0 & 0 & 63.04 & 36.96 \\
\hline
\end{tabular}

(단위: \%)
은 공간 도메인에서와 동일하다. 분산의 계산량 감소를 위 해서 (8)의 식을 다음과 같이 간략화 시킨다.

$$
\sigma^{2} \cong \sum_{u=0}^{3} \sum_{v=0}^{3}|F(u, v)| \quad(u, v) \neq(0,0)
$$

edge가 있는 영역으로 분류되면, 블록의 방향성은 다음 방법에 따라 수행한다. 먼저 방향성 분류를 위해 사용할 파 라미터 값, R1과 R2를 다음과 같이 정의한다.

$$
R 1=\frac{S R}{S C}, R 2=\frac{S C}{S R}
$$

현재 블록의 분산이 특정 문턱 값(T1) 보다 크면, 그 블록 은 특정 방향성을 갖는 블록으로 생각할 수 있다. 이것은 그 블록은 edge를 포함한다는 것을 의미하고, 그렇지 않으 면 flat한 영역이라는 것을 의미한다. 위의 사실에 근거하여 조건 1 을 정의하고, 이를 만족하면 블록은 edge를 가지고 있다고 판단한다.

\section{조건 1 (Flat 영역)}

$$
\sigma^{2}>T 1
$$

3.2장의 $\mathrm{DCT}$ 계수 분석에서 수직 방향에 대해서는 $\mathrm{SR}$ 의 비율이, 수평 방향에 대해서는 $\mathrm{SC}$ 의 비율이 가장 높게 나타 났다. SR이 $\mathrm{SC}$ 보다 크다면 그 블록은 수직 방향의 성분이 우세하고, 그렇지 않으면 수평 방향의 성분이 우세한 블록 으로 생각할 수 있다. 수직 방향이 우세할 때, $\mathrm{SC}$ 의 비중이 특정 문턱 값(T2)보다 크면 그 블록은 방향성이 뚜렷하지 않은 복잡한 블록 패턴가지는 영역으로 판단한다. 이를 조 건 2 로 정의하고 블록의 non-direction edge를 결정한다.

\section{조건 2 (Non-direction) \\ $\{S R(\%)>S C(\%)\} \cap\{S C(\%)>T 2\}$
$\{S C(\%)>S R(\%)\} \cap\{S R(\%)>T 2\}$}

수직 방향성이 우세할 때, R1이 특정 문턱 값(T3)보다 크 면 그 블록은 수직방향을 가지는 블록으로, 그렇지 않으면 


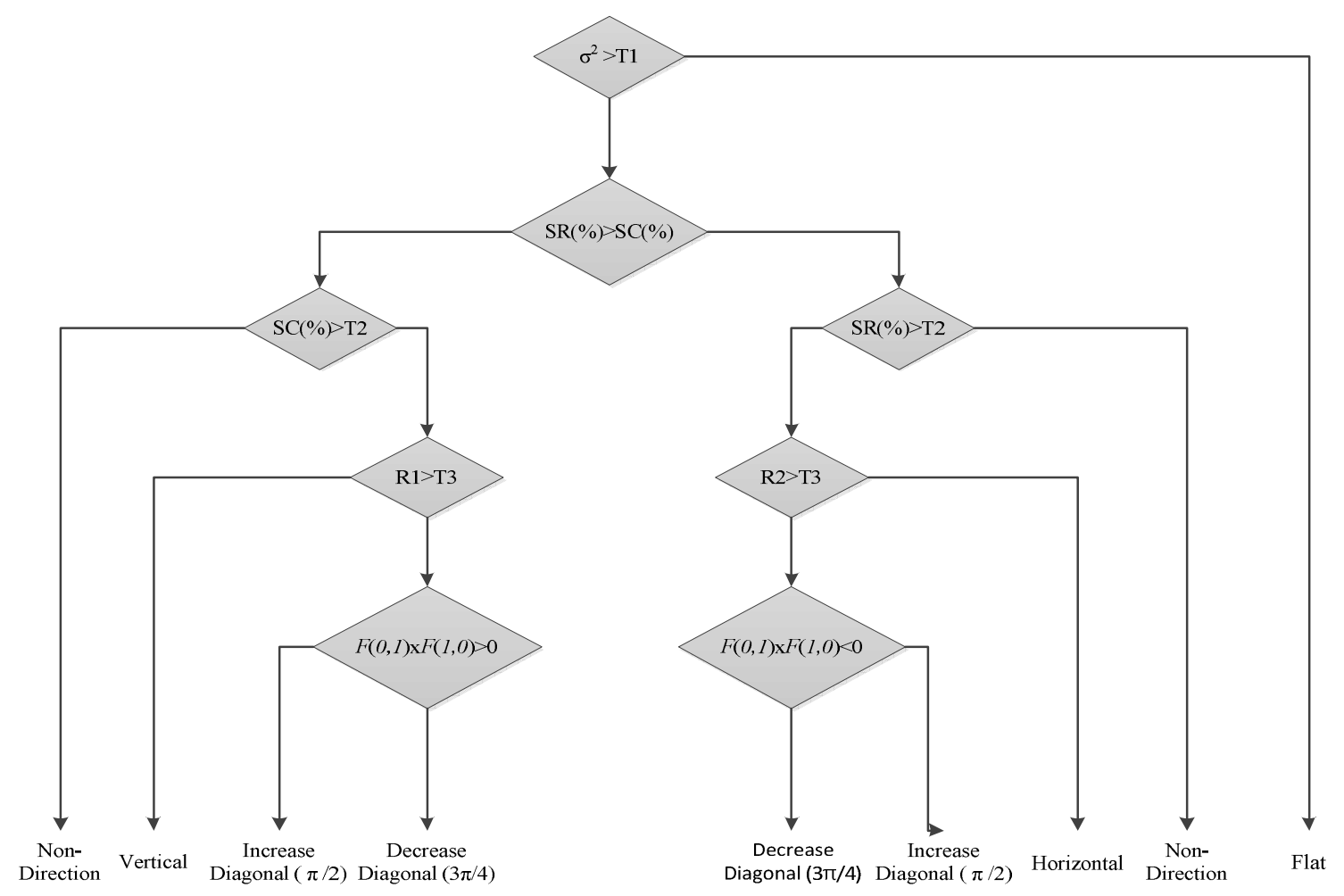

그림 4. edge 방향성 추출 알고리듬의 순서도

Fig. 4. The flowchart of the edge direction extraction algorithm

대각 방향을 가지는 블록으로 결정한다. 대각 방향의 경우 앞에서 말했듯이 $\mathrm{AC}$ 계수의 대칭과 반대칭인지를 파악해 서 $45^{\circ}$ 와 $135^{\circ}$ 방향성을 분류한다. 수평 방향이 우세한 경 우도 위와 동일한 방식으로 분류 한다. 이를 각각 조건 3 6 으로 정의한다.

\section{조건 3 (수직 방향)}

$$
\{S R(\%)>S C(\%)\} \cap\{R 1>T 3\}
$$

조건 4 (수평 방향)

$$
\{S C(\%)>S R(\%)\} \cap\{R 2>T 3\}
$$

조건 5 ( $45^{\circ}$ 방향)

$$
\{R 1 \text { or } R 2<T 3\} \cap\{F(0,1) \times F(1,0)>0\}
$$

조건 6 ( $135^{\circ}$ 방향)

$$
\{R 1 \text { or } R 2<T 3\} \cap\{F(0,1) \times F(1,0)<0\}
$$

그림 4는 edge 방향성 추출 알고리듬의 순서도를 나타
낸다.

\section{3. edge 방향에 기반한 적응적 업샘플링 알고리듬}

블록의 edge 방향성을 고려해 공간 도메인과 DCT 도메 인에서 적응적으로 필터를 적용한다. 먼저 flat한 영역에 대 해서는 DCT 도메인의 영 패딩 방법으로 업샘플링 한다. Flat한 영역은 대부분의 고주파 성분이 0 값을 가지기 때문 에 고주파 성분을 0 으로 패딩해도 블록 열화 현상이 거의 나타나지 않는다. 수직과 수평 방향에 대해서는 기존의 6탭 위너 필터를 이용한 하이브리드 보간 기법을 적용한다. 수직 방향의 경우 그림 5의 (a)와 같이 수직 방향으로 6-탭 필터를 적용하고, 수평 방향의 경우 수평 방향으로 필터를 적용한다. 예를 들어, 그림 5의 (a)에서 aa위치의 픽셀을 보 간하기 위해서는 수직 방향에 위치하는 $\mathrm{a}, \mathrm{b}, \mathrm{c}, \mathrm{d}, \mathrm{e}, \mathrm{f}$ 픽셀 에 필터를 적용해야 한다. 


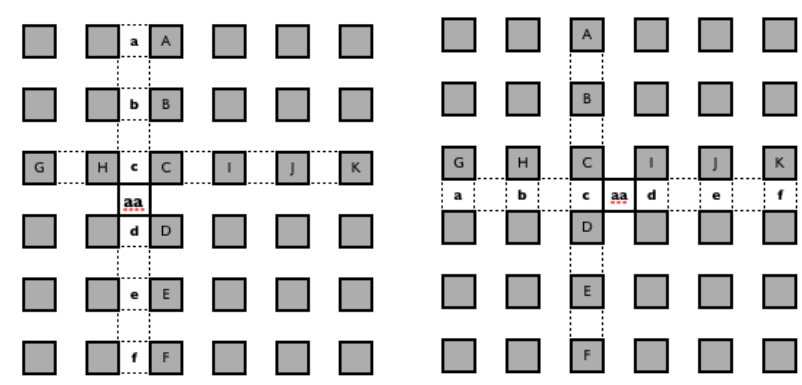

(a)

(b)

그림 5. 6-탭 위너 필터를 적용하는 이미지의 화소 위치: (a) vertical, (b) horizontal

Fig. 5. The position of pixel for 6-tap wiener filter: (a) vertical, (b) horizontal

대각 방향과 방향성이 없는 블록에 대해서는 새로운 8-탭 위너 필터를 사용한다. 기존의 8-탭 위너 필터 계수미는 다 음과 같다.

$$
\{-8,24,-48,160,160,-48,24,-8\} / 128
$$

필터의 탭 수가 증가하면 over-smoothing 현상이 증가할 수 있기 때문에 보간하고자 하는 화소와 인접한 픽셀에 더 많은 가중치를 주도록 필터 계수를 다음과 같이 바꾼다. 그 림 6은 기존의 필터 계수와 새로운 필터 계수의 주파수 응 답을 나타낸다.

$$
\{-9,25,-56,168,168,-56,25,-9\} / 128
$$

대각 방향에 대해서는 새로운 8-탭 위너 필터를 사용하여 하이브리드 방법으로 업샘플링 한다. 다른 방향에 적용한 방법과 유사한 방법으로 필터를 적용한다. 예를 들어, 그림 7 (a)에서 $\mathrm{a}$ 위치의 화소를 보간하기 위해서 $45^{\circ}$ 방향에 위치 한 8 개 화소인 $\mathrm{A}, \mathrm{B}, \mathrm{C}, \mathrm{D}, \mathrm{E}, \mathrm{F}, \mathrm{G}, \mathrm{H}$ 에 필터를 적용한다. 이를 (13)에 나타내었다.

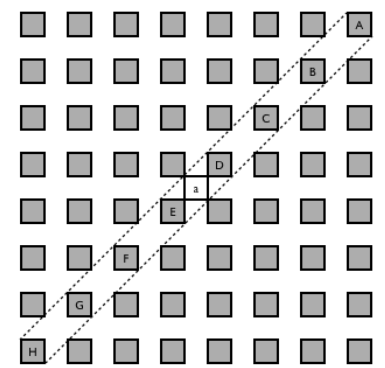

(a)

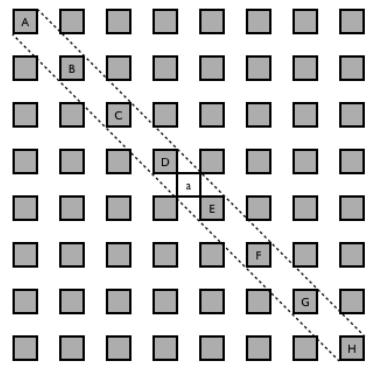

(b)
그림 7. 새로운 8-탭 위너 필터를 적용하는 이미지의 화소 위치: (a) vertical, (b) horizontal

Fig. 7. The position of pixel for new 8-tap wiener filter: (a) vertical, (b) horizontal

$$
\begin{aligned}
& (-9 A+25 B-56 C+168 D+168 E-56 F+25 G-9 H) \\
& / 128
\end{aligned}
$$

마지막으로 non-direction 블록에 대해서는 공간 도메인 에서 새로운 8-탭 위너 필터를 사용해 보간한 블록을 그대 로 사용한다. 제안하는 알고리듬의 edge 방향에 따른 보간 기법을 정리하여 표 2에 나타내었다.
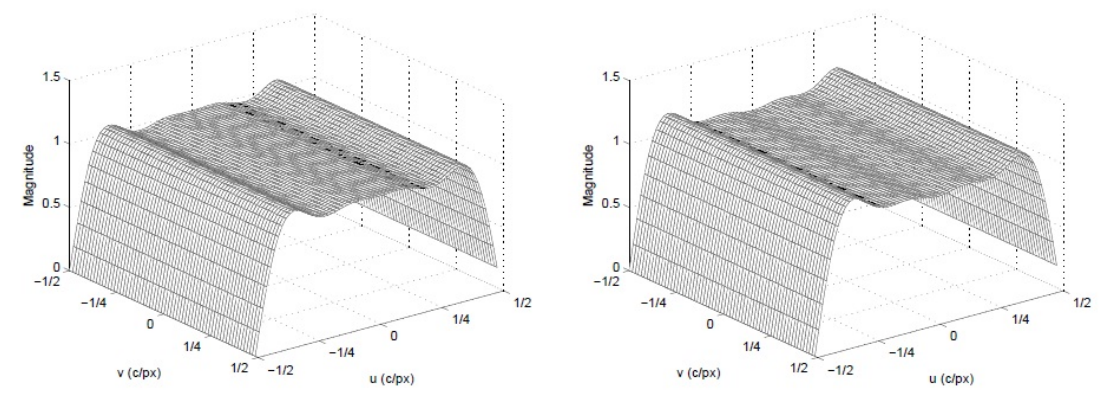

(a)

(b)

그림 6. 8-탭 필터의 주파수 응답: (a) 기존 필터, (b) 새로운 필터

Fig. 6. The frequency response of two 8-tap filters. (a) conventional 8-tap filter (b) new 8-tap filter 
표 2. Edge 방향에 따른 보간 기법

Table 2. Relationship of edge direction and its corresponding interpolation method

\begin{tabular}{|c|c|}
\hline Edge 방향 & 보간 기법 \\
\hline Flat & DCT 도메인에서 영 패딩 기법 \\
\hline $0^{\circ}$ (수평 방향) & 6-탭 위너 필터를 수평방향으로 적용한 하이브리드 기법 \\
\hline $45^{\circ}$ (대각 방향) & 새로운 8-탭 필터를 $45^{\circ}$ 방향으로 적용한 하이브리드 기법 \\
\hline $90^{\circ}$ (수직 방향) & 6-탭 위너 필터를 수직방향으로 적용한 하이브리드 기법 \\
\hline $135^{\circ}$ (대각 방향) & 새로운 8-탭 필터를 $135^{\circ}$ 방향으로 적용한 하이브리드 \\
\hline 기법
\end{tabular}

\section{IV. 실험 결과}

본 논문에서는 제안하는 알고리듬과 기존의 보간 알고리 듬에 대해 객관적인 성능과 주관적인 성능을 비교 하였다. 실험에는 그림 8의 Airplane, Baboon, Goldhill, Houses, Lena, Peppers의 정지 영상을 사용하였다. 실험은 먼저 512 x512 크기의 원본 이미지를 $256 x 256$ 크기의 저해상도 이
미지로 다운 샘플링 시킨다. 이 때, 다운샘플링은 SVC에서 사용되고 있는 DCT 기반의 다운 샘플링 필터를 사용한다. 다운 샘플링된 저해상도 이미지를 제안하는 알고리듬과 기 존의 보간 기법들을 사용해 업샘플링 시킨 후 원본 영상과 의 객관적인 화질과 주관적인 화질을 비교한다. 실험에서 사용한 문턱 값 $\mathrm{T} 1, \mathrm{~T} 2, \mathrm{~T} 3$ 는 각각 $45,35,5$ 이다.

표 3은 제안하는 알고리듬과 기존 보간 기법인 양 선형 (bi-linear), 영 패딩(zero-padding), 하이브리드(hybrid) 기

표 3. PSNR비교

Table 3. PSNR Comparison

\begin{tabular}{|c|c|c|c|c|c|}
\hline \multirow{2}{*}{ Images } & \multicolumn{5}{|c|}{ PSNR (dB) } \\
\cline { 2 - 6 } & Bi-linear & 6-tap & Zero-padding & Hybrid & Proposed \\
\hline Airplane & 27.50 & 27.87 & 30.58 & 30.86 & 30.97 \\
\hline Baboon & 22.25 & 22.52 & 23.36 & 23.47 & 23.59 \\
\hline Goldhill & 29.16 & 29.40 & 31.02 & 31.25 & 31.34 \\
\hline Houses & 21.37 & 21.67 & 23.18 & 23.49 & 23.60 \\
\hline Lena & 31.23 & 31.46 & 35.61 & 36.21 & 36.34 \\
\hline Peppers & 25.59 & 29.76 & 31.97 & 32.38 & 32.47 \\
\hline Average & 26.85 & 27.13 & 29.29 & 29.61 & 29.71 \\
\hline
\end{tabular}

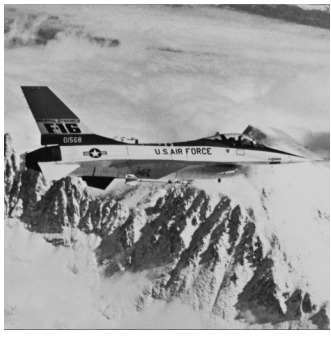

(a)

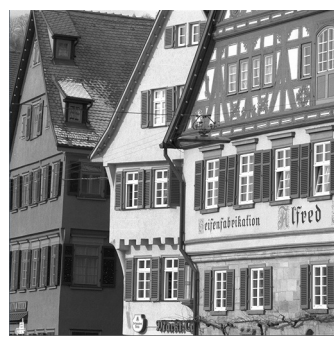

(d)

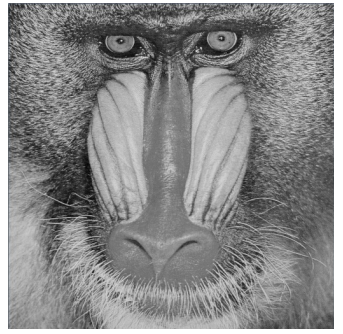

(b)

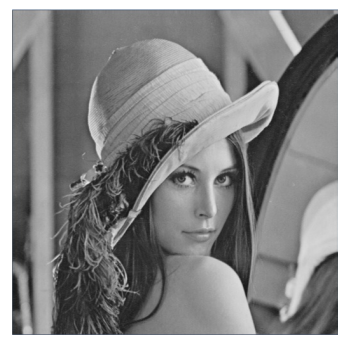

(e)

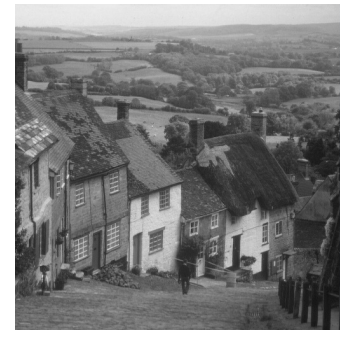

(c)

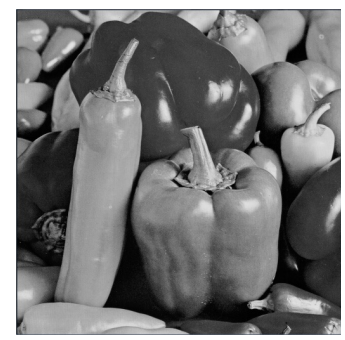

(f)

그림 8. 원본 영상: (a) Airplane, (b) Baboon, (c) Goldhill, (d) Houses, (e) Lena, (f) Peppers

Fig. 8. The original images: (a) Airplane, (b) Baboon, (c) Goldhill, (d) Houses, (e) Lena, (f) Peppers 
법들과의 PSNR 비교를 보여준다. 표 3으로부터 제안하는 알고리듬의 성능이 기존 기법들 보다 성능이 향상 된 것을 확인 할 수 있다. 제안하는 알고리듬은 하이브리드 기법에 비해 PSNR 측면에서 $0.09 \sim 0.13 \mathrm{~dB}$ 좋은 성능을 보여준다.
그리고 6-탭 위너 필터를 사용한 보간 기법에 비해 0.23 $0.73 \mathrm{~dB}$ 향상을, 영 패딩 기법에 비해 $1.07 \sim 4.88 \mathrm{~dB}$ 향상을 나타낸다.

그림 9,10 은 Lena 영상의 주관적인 화질 비교를 위한

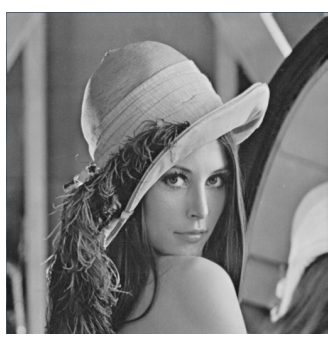

(a)

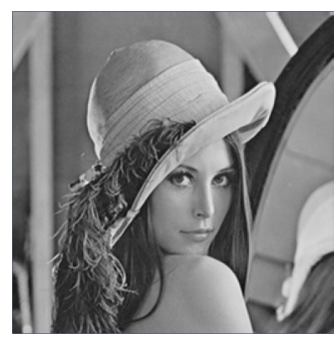

(e)

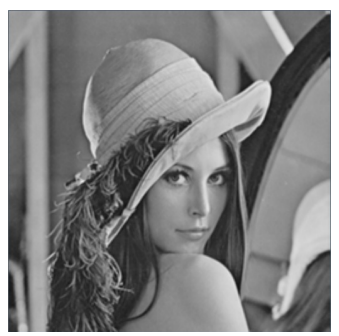

(b)

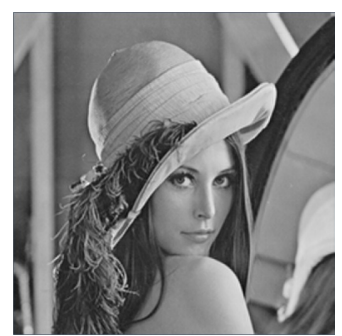

(f)

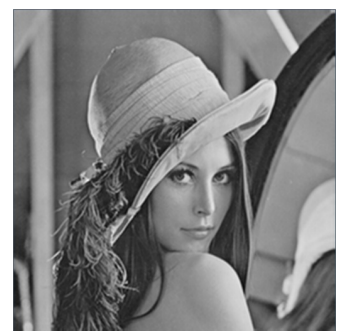

(c)

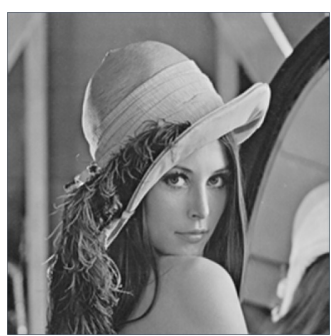

(g)

그림 9. 주관적인 화질 비교: (a) Original, (b) Bilinear, (c) 6-tap, (d) Zero-padding, (e) Hybrid, (f) Proposed

Fig. 9. The subjective quality comparison: (a) Original, (b) Bilinear, (c) 6-tap, (d) Zero-padding, (e) Hybrid, (f) Proposed

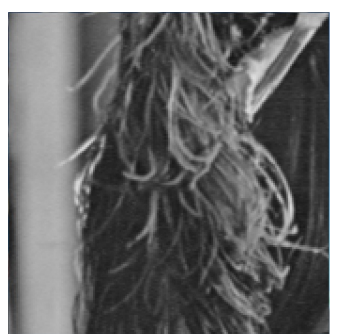

(a)

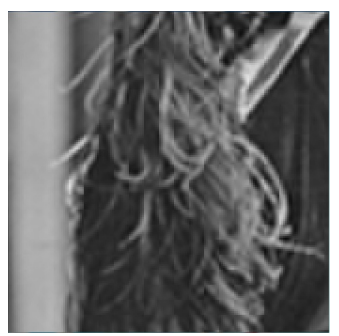

(d)

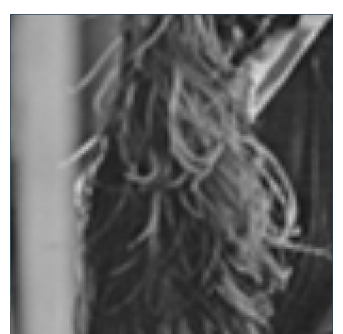

(b)

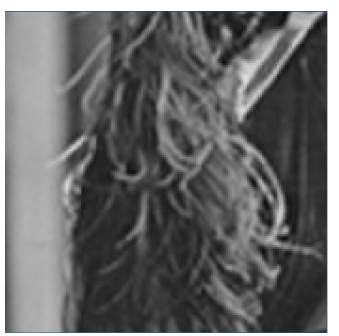

(e)

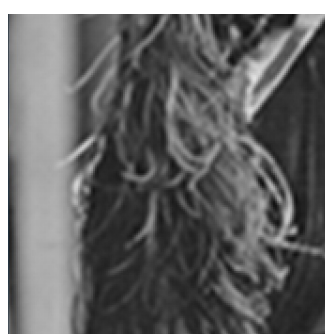

(c)

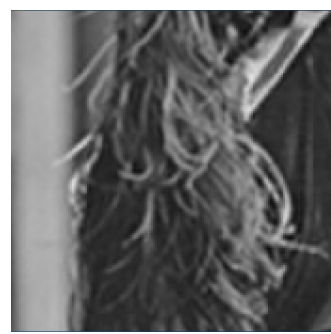

(f)

그림 10. 주관적인 화질 비교: (a) Original, (b) Bilinear, (c) 6-tap, (d) Zero-padding, (e) Hybrid, (f) Proposed

Fig. 10. The subjective quality comparison: (a) Original, (b) Bilinear, (c) 6-tap, (d) Zero-padding, (e) Hybrid, (f) Proposed 
영상이다. 제안하는 알고리듬은 영 패딩 기법에서 나타나 는 블록 열화 현상이 거의 나타나지 않는다. 그리고 공간 도메인에서 수행되는 보간 기법들에 의해 나타나는 oversmoothing 현상도 나타나지 않아 주관적인 화질 측면에서 도 좋은 성능을 나타낸다. 하지만, 기존의 하이브리드 기법 과의 주관적인 화질차이는 거의 나지 않는다.

\section{V. 결 론}

본 논문에서는 효과적인 이미지 업샘플링을 위해 블록의 방향성을 분류하기 위해 DCT 계수의 분포를 분석하였다. 분석한 결과를 바탕으로 블록의 방향성을 6 가지로 분류하 였다. 본 논문에서 분류한 6 가지 방향성은 평탄한 영역 (flat), 수평 방향, $45^{\circ}$ 대각 방향, 수직 방향, $135^{\circ}$ 대각 방향, 방향성이 없는 복잡한 영역(non-direction)이다. 제안하는 알고리듬은 블록이 가지는 방향성의 특징을 살릴 수 있도 록 공간 도메인과 DCT 도메인에서의 보간 기법을 블록 별 로 적응적으로 사용한다. 그리고 기존의 8-탭 위너 필터의 계수를 변형하는 새로운 8-탭 필터를 사용하였다. 보간하고 자 하는 화소 위치에 인접한 화소에 더 많은 가중치를 가지 도록 필터 계수를 조정하였다. 실험 결과로부터 제안하는 알고리듬이 주관적인 화질 측면의 향상과 함께 PSNR 측면 에서 기존의 하이브리드 기법에 비해 $0.09 \sim 0.13 \mathrm{~dB}, 6$-탭 필 터를 사용한 보간 기법에 비해 $0.23 \sim 0.73 \mathrm{~dB}$, 영 패딩 기법 에 비해 $1.07 \sim 4.88 \mathrm{~dB}$ 향상된 성능을 보여준다.

\section{참 고 문 헌}

[1] S. J. Park and J. C. Jeong, "Hybrid image upsampling method in the discrete cosine transform domain," IEEE Trans. on Consumer Electronics, vol. 56, no. 4, November 2010.

[2] R. G. Keys, "Cubic convolution interpolation for digital image processing," IEEE Trans. Acoust., Speech, Signal Processing, vol. ASSP-29, no. 6, pp.1153-1160, 1981.

[3] J. A. Parker, R. V. Keyon and D. E. Troxel, "Comparison of interpolation methods for image resampling," IEEE Trans. on Image Processing, MI-2, no.1, March 1983.

[4] T. M Lehmann, C. Gpmmer and K. Spotzer, "Survey: Interpolation methods in medical image processing," IEEE Trans. Medical Imaging, vol. 18, no. 11, pp. 1049-1075, November 1999.

[5] Advanced Video Coding for Generic Audiovisual Service ITU-T and ISO/IEC JTC1, Rec. H.264-ISO/IEC 14496-10 AVC, 2003.

[6] R. Dugad and N. Ahuja, "A fast scheme for image size change in the compressed domain," IEEE Trans. Circuits, Syst., Video Technol., vol. 11, pp. 461-474. 2011

[7] H. W. Park, Y. S. Park, and S. K. Oh, "L/M-fold image resizing in block-DCT domain using symmetric convolution," IEEE Trans. Image Process., vol. 12, no. 9, pp. 1016 --1034, Sep. 2003.

[8] I. Shin and H. W. Park, "Adaptive up-sampling method using DCT for spatial scalability of scalable video coding," IEEE Trans. Circuits Syst. Video Technol., vol. 19, no. 2, Feb. 2009.

[9] Z. Wu, H. Yu and C. W. Chen, "A new hybrid DCT-wiener-based interpolation scheme for video intra frame up-sampling," IEEE Signal Processing Letters, vol. 17, no. 10, October 2010.

[10] ITU-TRec. H.264/ISO/IEC 14 496-10 AVC, Mar. 2003.

[11] J. Ribs-Corbera, "Core Experiment on Motion Compensated Prediction: Accuracy and Inteprolation", ITU-T Q15-I-59, Oct. 1999.

[12] S. W. Park, J. H. Park, B. M. Jeon, H. W. Park, "Efficient Image Upsampling using Frequency Resolution Expansion Schemes in DCT Domain", The journal of broadcast engineering 2005, Vol. 10, No. 4, pp. 505-514, December 2005.

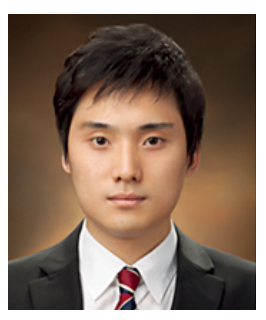

\section{김 재 훈}

- 2011년 2월 : 한양대학교 전자통신컴퓨터공학과 졸업(학사)

- 2011년 3월 현재 : 한양대학교 전자컴퓨터통신공학과 석사과정

- 주관심분야 : 비디오 압축, 영상처리 
저 자 소 개

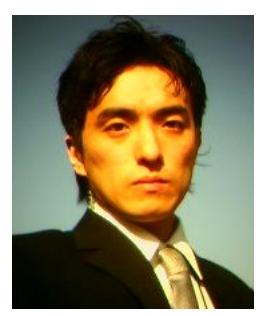

김 기 백

- 2008년 2월 : 세종대학교 정보통신공학과 졸업(학사)

- 2010년 2월 : 세종대학교 정보통신공학과 졸업(석사)

- 2010년 9월 현재 : 한양대학교 전자컴퓨터통신공학과 박사과정

- 주관심분야 : 비디오 압축, 영상처리

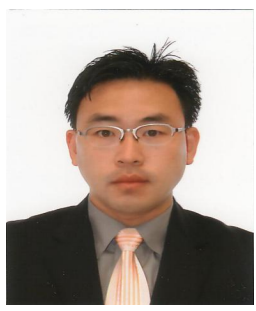

\section{전 광 길}

- 2003년 3월 : 한양대학교 전자전기컴퓨터공학과 졸업(학사)

- 2005년 2월 : 한양대학교 전자통신전파공학과 석사

- 2008년 8월 : 한양대학교 전자통신전파공학과 박사

- 2008년 9월 2009년 8월 : 한양대학교 전자통신전파공학과 박사후과정

- 2009년 9월 2011년 8월 : 캐나다 오타와대학 정보기술대학(SITE) 박사후과정

- 2011년 11월 2012년 2월 : 일본 니이가타 대학 국제과학기술대학원 조교수

- 2012년 02월 현재 : 인천대학교 임베디드시스템공학과 조교수

- 주관심분야 : 영상처리, 인공지능, 회질개선, 영상압축

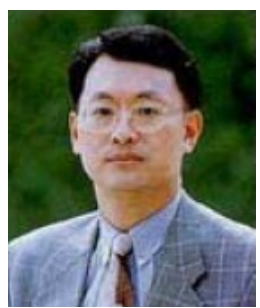

\section{정 제 창}

- 1980년 2월 : 서울대학교 전자공학과 졸업

- 1982년 2월 : KAIST 전기전자공학과 석사

- 1990년 : 미국 미시간대학 전기공학과 공학박사

- 1980년 1986년 : KBS 기술연구소 연구원 (디지털 및 뉴미디어 연구)

- 1990년 1991년 : 미국 미시간대학 전기공학과 연구교수 (영상 및 신호처리 연구)

- 1991년 1995년 : 삼성전자 멀티미디어 연구소 (MPEG, HDTV, 멀티미디어 연구)

- 1995년 현재 : 한양대학교 전자통신컴퓨터공학과 교수 (영상통신 및 신호처리 연구실)

- 1998년 11월 : 과학기술자상 수상

- 1990년 12월 : 정보통신부장관상 수상

- 2007년 : IEEE Chester Sall Award 수상

- 2008년 : ETRI Journal Paper Award 수상

- 2011년 5월 : 제 46 회 발명의 날 녹조근정훈장 수훈

- 주관심분야 : 영상처리, 영상압축, $3 \mathrm{DTV}$ 